\title{
Routine Regrets: Over Disclosure and Self-violations of Privacy in Social Media Spaces
}

\author{
Matthew P. Hartwell
}

Follow this and additional works at: https://researchrepository.wvu.edu/etd

\section{Recommended Citation}

Hartwell, Matthew P., "Routine Regrets: Over Disclosure and Self-violations of Privacy in Social Media Spaces" (2018). Graduate Theses, Dissertations, and Problem Reports. 5777.

https://researchrepository.wvu.edu/etd/5777

This Thesis is protected by copyright and/or related rights. It has been brought to you by the The Research Repository @ WVU with permission from the rights-holder(s). You are free to use this Thesis in any way that is permitted by the copyright and related rights legislation that applies to your use. For other uses you must obtain permission from the rights-holder(s) directly, unless additional rights are indicated by a Creative Commons license in the record and/ or on the work itself. This Thesis has been accepted for inclusion in WVU Graduate Theses, Dissertations, and Problem Reports collection by an authorized administrator of The Research Repository @ WVU. For more information, please contact researchrepository@mail.wvu.edu. 
Routine Regrets: Over Disclosure and Self-Violations of Privacy in Social Media Spaces

\author{
Matthew P. Hartwell
}

Thesis submitted

To the Eberly College of Arts and Sciences

At West Virginia University

Master of Arts in

Sociology

\author{
Joshua Woods, Ph.D., Chair \\ Katie Corcoran, Ph.D. \\ Jason Manning, Ph.D.
}

Department of Sociology and Anthropology

\author{
Morgantown, West Virginia \\ 2018
}

Keywords: Social Media, Disclosure, Privacy, Regret

Copyright 2018 Matthew P. Hartwell 


\section{Abstract \\ Routine Regrets: Over Disclosure and Self-Violations of Privacy in Social Media Spaces}

\section{Matthew P. Hartwell}

The theory of ritualized media is applied to computer mediated communication to explain unintended consequences of routinization in social media spaces connected to patterns of use and network growth, creating an increased opportunity for self-violations of privacy. The unintentional self-violation of a digital user's privacy of information, thoughts, and behavior in part stems from interconnected structural components of a user's networks as well as the situational constraints they experience while utilizing social media. This study found that as networks increased in complexity, both in volume and diversity, SNS users experienced a higher likelihood of posting information that they later came to regret due to over-disclosure.

Additionally, specific situations, specifically emotional hot states and the use of intoxicants, also led to higher likelihood of a self-violation of privacy. By identifying specific risk factors that may influence the likelihood of committing self-violations of privacy in digital spaces this study hopes to spur increased digital safety for social media users. 


\begin{tabular}{|c|c|}
\hline Title Page & i. \\
\hline Abstract & ii. \\
\hline Table of Contents & iii. \\
\hline Introduction & 1. \\
\hline Self-Violations of Privacy & 2. \\
\hline The Audience: Real or Imagined & 3. \\
\hline Self-Violations of Privacy in Digital Spaces & 3. \\
\hline Methodology: & 5. \\
\hline - Sampling Frame & 5. \\
\hline Measures & 6. \\
\hline User Information & 6. \\
\hline Disclosure and Privacy & 6. \\
\hline- SVP & 7. \\
\hline Network Complexity & 7. \\
\hline Social Media Use & 8. \\
\hline SNS Behavior & 8. \\
\hline - SNS in Situations & 9. \\
\hline - Data Management and Analysis & 9. \\
\hline Results: & 10. \\
\hline - Descriptive Statistics & 10. \\
\hline - Bivariate Analysis & 11. \\
\hline - $\quad$ Multivariate Analysis & 14. \\
\hline Discussion: & 15. \\
\hline - More Exclusive Networks & 16. \\
\hline - Social Media Use & 16. \\
\hline - Risky Situations & 17. \\
\hline Conclusion & 18. \\
\hline References & 19. \\
\hline Appendix A: Tables & 22. \\
\hline - R1: Sample Demographics & 22. \\
\hline - R2: Reported Regret by Demographics & 23. \\
\hline $\begin{array}{l}\text { R3: Reported Regret for Network Complexity between High and Low } \\
\text { Variable Groupings }\end{array}$ & 24. \\
\hline - R4: Reported Regret by High and Low Frequency Use and Behavior Groups & 25. \\
\hline $\begin{array}{l}\text { - R5: Reported Regret by High and Low Frequency SNS Use Groups in } \\
\text { Situations }\end{array}$ & 26. \\
\hline - $\quad$ R6: Logistic Regression Models for Self-Violations of Privacy & 26. \\
\hline Appendix B: Survey & 27. \\
\hline
\end{tabular}




\section{Introduction:}

On December 20 ${ }^{\text {th }}, 2013$, Justine Sacco was boarding a flight from London's Heathrow airport heading to Cape Town, South Africa. Justine was 30 years old, received her B.A. in Philosophy from Tulane University, and was a senior director of communications for the public relations and marketing firm of IAC. As Justine waited to board her flight to Cape Town, she had been engaging in social media use via Twitter. Her final tweet before boarding the plane stated, “Going to Africa. Hope I don't get AIDS. Just kidding. I'm white!" It was not until her flight landed in Cape Town hours later that she realized the scope of her actions.

Unbeknownst to Justine, her tweet had been shared (retweeted) by enough people to make her the number one trending tweet on twitter. Most users who retweeted her post added comments expressing disgust and anger at the flippant disregard which Ms. Sacco had shown the AIDS epidemic, global racial inequality, and her own privileged position. Many wondered how an educated, successful woman whose career is to ensure that other people present a positive image and avoid negative press, could be guilty of such a heinous failure of impression management. Nearly all were calling for her termination, including co-workers who did not want her representing IAC as a whole; and she was fired shortly after arriving in Cape Town and returning to phone service where she was able to realize just how large of an impact 114 characters or less can have on an individual's life (Ronson 2015).

But Justine's story is not an isolated incident, merely one of the more spectacular examples of things people wish they hadn't said. Social networking sites (SNS) are populated with stories of individuals who have shared information through highlighting the failure or inability to simultaneously observe all socially expected behaviors of their actual audience, leading to negative interactions with a range of impacts on individuals within society (Litt 2012)While many online denizens are at least minimally aware of the risks associated with invasions of digital privacy and the potential for their information to be taken, stolen, or used for malicious ends, many are not aware that the more benign actions of posting and interacting in digital spaces can also have unintended consequences.

While millions of dollars go into the development and understanding of ways in which to protect the digital privacy of online citizens from others, much fewer resources are invested in understanding and preventing how to protect users from themselves (Buchanan et al. 2007; Joinson et al. 2010; Norberg and Horne 2007). Privacy research tends to focus on digital pirates stealing personal, banking, and other compromising information for their own purposes, however individual disclosure which is often seen as rational with an assumption that users are cognizant of the consequences of their behavior remains understudied (Custers, van der Hof, and Schermer 2014; Taddicken 2014). When information is freely shared by users, the possibility exists that it may self-violate the privacy (Self-violation of Privacy, SVP) of their information, thoughts, and beliefs to varying levels of unintended consequence.। 


\section{Self-Violations of Privacy:}

What we choose to disclose (Chelune 1975) is based in part on our perceptions of our audiences. Who we believe is "listening" and can "hear" what we share allows us to determine what is and is not appropriate to disclose. Additionally, the information people choose to share is highly personalized and relies on intent, mood, and situation (Derlega and Chaikin 1977; Kim and Dindia 2011). The process of self-disclosure occurs through both active rationalization and internalized conceptualizations of what is deemed to be socially appropriate. SNS users are socialized into an understanding of online behaviors that are acceptable and which are deviant in specific settings (in particular to whom one is sharing information with), and internalized to varying degree based on the agents of socialization (Bazarova and Choi 2014; Mesch and Beker 2010). This disclosure of information creates an image of the actor to the rest of their audience that is the basis for our presentation of self (Goffman 1959). That performance is also mediated by the self we perceive others to view us as (Cooley 1964).

The appropriate information one could share is then both influenced by situation and audience (Brake 2009; Litt 2012; Oolo and Siibak 2013). For example, it may violate some standards of normative behavior to discuss topics of past sexual behavior with one's mother, while the same behavior would be expected of "macho" men hanging out together. Disclosure of sexual activity to a church congregation might also violate multiple normative expectations, but to "confess" one's pre-marital sexual behavior as sin would be expected in the confessional. In the context of situation and audience, both matter in avoiding failures of impression management.

A situation in which private information is shared, or a self-violation of privacy (SVP), arises when there is an incongruity between speakers and audiences in communication. Utilizing the information at their disposal, individuals encode their message into symbols that are intended to be interpreted or decoded by others in the manner intended and with the same meaning as that of the encoder. While one may assume that their audience will interpret the image as intended and interpret the self-disclosure of information and images through the same subjective lens, this might not always be the case (Tufekci 2007; Zhou, Wang, and Chen 2016). These situations of SVP take multiple forms based on the intent of the messages, content of the message, and the interpretations by audiences (Wang et al. 2011; Zhou et al. 2016).

SVP may take the form of disclosure of personally identifying information, attitudinal dispositions, or evidence of past behaviors. Personal information disclosed may be proprietary to the individual, social identification or financial information that could allow others to misuse or take advantage of for personal and economic gain. In addition to informational disclosures, SVP can also occur when individuals disclose messages that convey personal attitudes, or affective dispositions about a multitude of topics. SVP may also include information about past behaviors that lead to the consequences of those actions. An SVP of behaviors can provide information to others about behaviors that an individual should or should not have been engaging in. 


\section{The Audience: Real or Imagined:}

Whether it is information, attitudes, or behavior, SVP carries the potential for consequences based on what is shared and who has access to it. While our performance is crafted for the imagined audience (Litt 2012; Oolo and Siibak 2013), to avoid SVP that perception of audience must match the actual audience (Goffman 1959),). This gap between our perception of the audience and actual composition is a source for potential risk of SVP. But there are multiple permutations for how this occurs.

An unknown audience would be a party that has access to an individual's communication without their knowledge. That could include intentional concealment in order to purposefully monitor communications, or bystanders within the social space that may overhear what is communicated (Bernstein et al. 2013). Without the knowledge about the presence of certain individuals within the audience, perception of the imagined audience becomes flawed from the actual audience. Here the discrepancy between real and imagined exposes the discloser to SVP if the information, attitudes, or behaviors shared are appropriate for the imagined audience but not the unknown parties in the actual audience.

Similarly, it also possible for the communicator to overlook audience members when disclosing information. Specific audience members may vary in their level of salience to the communicator, which can be influenced by levels of interaction (Derlega and Chaikin 1977; Joinson et al. 2010). This may lead to an SVP of attitudes, behaviors, or information. SVP can also occur when we know who all the members of the real audience are but misperceive what information they will deem acceptable to disclose. Cognition of expected behavior and awareness of the norms of social spaces influences actual behavior (Case, Sparks, and Pavey 2016; Doster 2013; de Hooge, Zeelenberg, and Breugelmans 2011). Individuals who bring into social spaces an expectation of what behavior is acceptable, without cognition of alternate expectations expose themselves to risk of SVP.

Lastly, it is also a potential pathway to SVP for communications to contain unintended information that is not appropriate to the audience. In the previous case of cognitions, individuals intentionally shared information under the impression it was appropriate for the audience. However, in other cases, the message that is disclosed contains information that wasn't known or intended for the audience to receive (Debatin et al. 2009). This form of SVP is most likely to contain either information or records of behaviors, especially in digital social spaces where the sharing of images is prevalent.

\section{Self-Violations of Privacy in Digital Spaces:}

SVP can occur in multiple ways, but only in relation to an audience. Either an individual couldn't, forgot, or failed to accurately imagine who their audience was in relation to the actual audience. SVP may also have occurred because unintended information was included in the message to an audience (Debatin et al. 2009; Everett 2010). Social Media outlets allow for the immediate sharing of thoughts and images of our behavior to ever expanding audiences. This 
ability to share information about ourselves is one of the reasons that draws us to these outlets (Bareket-Bojmel, Moran, and Shahar 2016). However, it is also exposes us to great risk of oversharing information about ourselves, enabling a "self-violation of privacy" (SVP) of our true thoughts and behaviors.

It is intended to understand what leads to the creation of situations in which one presents an image or portrayal of themselves to others with one expectation but fails to accomplish this with potential negative consequences. Because of these opportunities for failure in which the presenter misinterprets their imagined audience from the actual one, the resulting response has the opposite of its intended effect and creates negative outcomes for both the projector and audiences of the interaction. Drawing on Rubin's (1984) theory of ritualized media, some scholars argue that interacting on social media can become a habit or routine that reduces the user's cognitive attention and increases the chance for SVPs. (Couldry 2003; Debatin et al. 2009; Rubin 1984).

The ritualization and routinization of social media use provides and explanation for exposing social media users to the potential pitfalls of performing for unintended audiences. Social networks grow in both size and diversity increasing cognitive demands on users to match imagined audience to the actual audience, while actual cognitive resources dedicated to social media use are reduced via ritual and routine, exposing users to the risk of performing for unintended audiences when imagined and actual audiences are misaligned.

Primarily, the larger a social network grows, it becomes increasingly difficult to account for all the people who comprise that social network and act as audience. Cognitive biases and schematic processing take over imagining the audience, and the more prolific or immediate members of the audience come to represent the entire audience (Bareket-Bojmel et al. 2016; Litt 2012; Oolo and Siibak 2013). The inability due to network volume to account for all audience members would create an expected increase in reported rates of SVP via this inability to perceive audience members that would consider certain forms of disclosed information to be deviant, or to be someone that users did not want to have that information.

\section{H1: Network volume and self-violations of privacy are positively correlated.}

Secondly, heterogeneity represents high levels of complexity of a user's network. Users whose networks are filled with ties reflecting many roles will be more susceptible to SVP at a higher rate than users who maintain relatively homogenous social media spaces. Those who commit SVP because they fail to account for alternative sets of norms, possibly do so as a failure to consider how the information shared may be received and interpreted by those occupying a multitude of social roles. Particularly the inclusion of varying roles with dissimilar normative standards, i.e. employer and friend or partner and co-worker, would complicate the process of forming a cognitive schema specific to one's personal network that meet the lowest common standard for avoiding SVP within the framework of ritualized media where routine behavior has decreased the level of cognitive energy devoted to this process.

\section{H2: Network diversity and self-violations of privacy are positively correlated.}


Individuals who engage in social media use while engaged in non-social media behaviors risk committing SVP by sharing cognitive energy between multiple tasks. Additionally, the frequency and modes of social media use shape and frame the information that is shared. Individuals who utilize social media more frequently may expose themselves to greater risk of SVP by volume alone, however, it is equally likely that frequent use can build competency or breed familiarity. It appears more likely that the types of social media use in combination with frequency provide the greatest opportunity for SVP. Individuals who utilize social media more frequently to share opinions, mood or feelings, and pictures of themselves and others also expose themselves to greater risk of SVP

\section{H3: Self-violations of privacy are positively associated with frequency of use for specific behaviors on SNS.}

Finally, specific situational constraints with factors that reduce cognitive ability would be expected to increase a user's vulnerability to SVP. The use of drugs and/or alcohol while engaging in social media complicates the process of imagining one's audience and the appropriate information that one should disclose. Further, the sharing of images of one engaging in these behaviors constitutes an SVP of behavior in which multiple negative consequences exist. In addition to mind altering substances, internal affective states, in particular high emotional or "hot" states (Wang et al.) interrupt the cognitive process of imagining one's audience, allowing elation or anger to lead one to share information without thinking through the full implications of doing so.

\section{H4: Self-violations of privacy are positively associated with frequency of use during emotional "hot" states. \\ H5: Self-violations of privacy are positively associated with frequency of use while engaged in drug and/or alcohol use.}

\section{Methodology:}

Survey methodologies have widely been used to collect information about the ways in which individuals use social media outlets to communicate and project an image of self to others (Bazarova and Choi 2014; Berger 1998; Groth et al. 2017).The ability to collect a large number of cases for comparison highlights the trends and patterns of use that help to explain much of the behavior in social media spaces. While focusing on quantitative measures does not provide the individual rationalizations for a case by case explanation of self-violations of privacy, it will serve to highlight the commonalities that may serve as situational or structural causes of SVP.

\section{Sampling Frame:}

The current trends within social media use purport that the dominate demographics of users fall within the eighteen to twenty-nine-year-old age range (Duggan 2015) due to level of activity within economic, political, and social arenas. Further focus was directed on those ages eighteen through twenty-three as they are currently undergoing a process of socialization and 
internalization of new norms and expectations. Additionally, social media users age 18-23 predominately fall into the category of technologically adept group referred to as digital natives. These individuals were socialized in a technological framework in which the internet, social media, and online interaction have always existed. Despite age restrictions, nearly $60 \%$ of children begin utilizing social media by age 10 , resulting in the average college aged social media user having approximately a decade of experience.

The sampling frame chosen for this study was the undergraduate population of a mideastern land grant university, providing the research team with candidates that fit within age range of eighteen to twenty-three. The demographic composition of this university is predominately white $(81 \%)$, evenly split between male and female students, having an equivalent number of students across ages within the target sample frame, and approximately $55 \%$ of students are from out of state (College Factual 2013). This data is used to demonstrate a sample representative of similar institutions generalizable and comparable to similar university settings.

The current combined undergraduate and graduate student enrollment at this institution is 30,000 . Dissemination of the survey to the entirety of our sample frame utilized an electronic survey format to encourage the completion through ease of access. The survey instrument was created and hosted electronically and distributed to the sample frame via electronic mail with a link to the hosting site where the survey instrument could be completed. The opportunity to receive compensation in the form of a gift card was presented to respondents. The recipients of these gift cards were chosen randomly from the pool of respondents who completed the survey and opted-in to the drawing.

\section{Measures:}

\section{User Information:}

Respondents were prompted to provide basic demographic information about themselves for the purpose of identifying and controlling for differences among specific groups within the sampling frame. Respondents were prompted to indicate their age, sex, race, student status, and grade level.

\section{Disclosure and Privacy:}

A measure for individuals general concern for online privacy was collected. Respondents were asked to indicate to what extent the following prompts described themselves:

- In general, I am concerned about my privacy while using the internet.

- I am concerned about online identity theft.

- I am concerned about people online not being who they say they are.

- I am concerned about people I do not know obtaining personal information about my online activities.

These prompts were captured on a 5-point Likert scale from 0 (Does not describe me well) to 4 (Describes me extremely well). Scores for each of these prompts were combined to create an overall score measuring individual's general concern for online privacy and security. 
Individual's scores for general willingness to disclose and concern for online privacy/security are intended to serve as control variables to isolate the influence of network, situational, and affective variables on SVP. These measures were adapted from the "Online Privacy Concern and Protection" (PCP) scale created by (Buchanan et al. 2007) and the Adapted Scale for Online Privacy Concern and Protection for Use on the Internet (APCP) (Taddicken 2014).

\section{SVP:}

SVP is the main dependent variable of this study. Respondents were asked prompts if they ever felt they had committed an SVP and will be given an example situation for comparison. Wang et al. (2011) approach this variable utilizing the prompt "have you ever posted something on a social network and then regretted doing it"? Regret is an outcome of SVP and allows for a marker to identify when it has occurred. Respondents that indicated regret occurred were asked to recall the total number of instances that they can recall.

\section{Network Complexity:}

Cohen's social network index provides starting point for measuring both the volume of social media user's networks and the diversity of network ties they contain (Cohen et al. 1997). This is accomplished by deploying a measure of actual number of people in the social network as a measure of volume, and the number of high contact roles as a measure of network diversity. Similar network measures for social media platforms were used by Litt et al. (2014) to study Facebook audience sizes via prompt asking for total number of Facebook friends, and identifying eleven categories of possible roles that ties can be categorized into.

Separate prompts directed respondents to provide the total number of Facebook friends, Twitter and Instagram followers. These variables were combined into a composite variable expressing individual's total estimated network (TEN). It does need to be noted that Bernstein et al. (2013) has previously found that social media users grossly underestimate their audience size, noting that users estimated audiences at $27 \%$ of actual size. This was addressed by allowing respondents to access their social media and recover accurate information about number of contacts.

Network diversity was captured by prompting respondents to indicate which of the eleven distinct high contact roles were present within their combined networks across the three social media platforms. These roles included:

- Partner/Spouse

- Family

- Friends

- Acquaintances

- Classmate

- Teacher/Professor 
- Co-worker

- Boss/Employer

- Potential Employer

- Unknown

- Other

The total number of distinct high contact social roles was collected for each respondent and expressed as the total number of present roles indicated. This variable provided a measure of the diversity of networks (DON) for each respondent.

\section{Social Media Use:}

The survey instrument directed respondents to indicate how frequently they used social media. This measure provides an indicator of overall activity on each of the social media platforms. Respondents were asked to indicate their frequency of use of Facebook, Twitter, and Instagram along an ordinal scale of daily, 4-6 times a week, 2-3 times a week, once a week, or never. These categories were reverse scored and coded zero to four, corresponding zero to never and four to daily. The scores were combined across platforms to provide a scale of total social media use.

Utilizing the same ordinal scale, respondents were prompted to indicate how frequently they utilized any of the three social media platforms for specific forms of disclosure. Individuals were asked "how often do you post Facebook status updates, Tweet, or post to Instagram"; and "how often do you post images of yourself on social media?" The first prompt provides an indicator of how frequently individuals disclosed text-based information that includes information about themselves, while the second captures instances of image-based information about activities, behaviors, and locations that individuals have engaged in or been present at.

\section{SNS Behavior:}

Moving beyond general SNS use, respondents were asked to indicate to what extent that they engaged in specific behaviors via SNS. These specific behaviors covered a range of relational communication, forms and types of information shared, and purpose for disclosure. The purpose was to identify what if any specific behaviors were more or less likely to shape impression management and disclosure and impact the likelihood of SVP. SNS users were prompted to indicate frequency along a five-point Likert scale from none at all to a great deal of SNS use for the following behaviors:

- Communicate directly with friend(s).

- Communicate directly with family.

- Communicate with co-workers about work related issues.

- Like other's posts.

- Share life events (birthdays, anniversaries, births/deaths). 
- Share recent activity within 1-2 hours.

- Share past activity older than 2 hours.

- Share photographs of self.

- Share photographs of family.

- Share photographs of friends.

- Share current feelings/mood.

- Express non-political personal opinions.

- Express personal political opinions.

- Seek out job opportunities.

- Express frustration/vent.

\section{SNS in Situations:}

In order to understand the context in which SNS users are situated when they are sharing information and how those environmental and situational contexts influence disclosure, respondents were asked to indicate how frequently they used SNS in a variety of situations. These situations included the absence or presence of select individuals who may be present when using SNS. SNS use while at multiple locations including two that one would frequently spend time in and one that most individuals rarely find themselves in was measured. SNS use in social settings included while at one on one events and another for events with multiple attendees. Respondents were also asked to indicate how frequently they used SNS while under the influence of drugs and alcohol and immediately following events that could trigger "hot states."

Using a five-point Likert scale from never to always, respondents were prompted to indicate how frequently they used social media while in the following situations:

- While alone.

- While spending time with family.

- While spending time with friends.

- While at work.

- While at home.

- When on vacation.

- On a date.

- At a gathering (Party, Wedding, etc.).

- While drinking alcohol.

- While using recreational drugs.

- After arguing with friend or family member(s).

- After receiving good news.

- After receiving bad news.

\section{Data Management and Analysis:}

Distribution of the survey instrument yielded a return of 980 responses. This data was sorted and combed for completion and authenticity of responses. Incomplete surveys and surveys that failed to respond to dependent variables resulted in the removal of 148 cases from the initial 
sample. The sample was further restricted to cases that fit the 18-23 age range laid out in the methods section, removing 171 cases that fell outside of this age range. Additionally, surveys in which it was apparent that the respondent was being insincere in their responses were also dropped from the sample. These included respondents who indicated that episodes of regret had occurred in the range of 1000+ instances as hyperbole and not an accurate representation of actual instances, five cases in total for this reason. The result of these actions provided a sample of 658 respondents.

Dichotomous variables were created for each independent and control variable, by sorting respondents into a low category and a high category. Network volume measures were separated at the means for each variable. Network relationships were dummy variables indicating whether or not the relationship was present in the network. General use, specific use, and behavior measures sorted respondents into the low category if at or below the median and high if above the median. The exception to this was made for communicating with friends, liking other's posts, and share past activity which included the median in the high category due to response variability. The measures for frequency of use in specific situations was separated into low category at less than at least half of the time, and high category at half of the time or greater.

\section{Results:}

\section{Descriptive Statistics:}

The mean age of respondents was 19.9 years and slightly right skewed on the range of 18-23 year. The sample was overwhelmingly female, roughly $70 \%$. Racial breakdown was predominately white with minor representation in the other racial categories, $81 \%$ with $3-4 \%$ per each other category. (again, give percentages). Nearly all respondents were full time students $(97 \%)$ and breakdown by grade level was nearly uniform with a skew towards underclassmen. For complete demographic breakdown please refer to table R1.

A slight majority of the sample, $56.3 \%$, reported that they had posted some information via social media and regretted doing so. $60.3 \%$ of female respondents had reported regretting a post while only $48.2 \%$ of males indicated that this had occurred. Reported regret across ages was very nearly uniform with minor variation across a range of $51.6 \%$ through $61.5 \% .56 .54 \%$ of White, $57.89 \%$ of Black, $52.63 \%$ of Latino, $46.43 \%$ of Asian, and $73.68 \%$ of Other race respondents indicated they had posted something they later regretted. $56.25 \%$ of full time students reported a regrettable post, while $61.54 \%$ of part time students responded yes to a regrettable post. The proportion of respondents who indicated a regrettable post by grade level was roughly uniform ranging from $53.06 \%$ to $61.90 \%$.

Facebook users reported a mean of 575.17 friends, with a standard deviation of 1,368.41. Instagram users returned a mean of 630 followers, but with smaller variation in group with a standard deviation of 625.65. Twitter users had the smallest mean number of connections, 418.68 , but the largest variation with a standard deviation of 2533.78. A combined total estimated network (TEN) variable was created by combining these three measures and produced a mean TEN of 1479.45 with a standard deviation of 1341.03 . 
At least $90 \%$ of all respondents indicated they had friends, acquaintances, or family, in their network. Roughly $85 \%$ of individuals responded that their partner or spouse was in their online networks. Approximately $95 \%$ of respondents indicated that classmates were included in their networks, but only $68 \%$ had connected digitally with a teacher or professor. Nearly $78 \%$ of individuals reported the presence of co-workers in their networks, yet only $45 \%$ had included their boss or employer, and only $24 \%$ indicated they had connected with potential employers.

$30 \%$ of users also reported that they had unknown people or strangers in their online networks. Less than one percent of respondents indicated there was a relationship other than those provided, and these responses included local business they had connected with for promotional reasons (deals or coupons). A composite score of the total number of relationships (diversity of networks, DON) within each individual's network was created from these responses. The mean number of relationships for this sample was 7.13 relationships, with a standard deviation of 1.82 .

The median response for Facebook usage was 4-6 times per week, however most respondents indicated they used Facebook daily. This pattern of use was the same for Twitter users, however users indicated that if they used Instagram they did so more frequently with both the median and mode response being daily use. The median and mode responses for both frequency of textual/informational posts and image-based posts was daily for the sample.

Respondents were also asked to indicate how frequently they utilized SNS in specific situations. Survey responses indicated that individuals accessed SNS frequently while at home, less frequently while at work, and sometimes while on vacation. SNS use at gatherings or on a date was reported as infrequent. The use of SNS while engaged in the use of alcohol or drugs were situations that respondents indicated happened either never or sometimes for most of the sample. However, just over two-thirds of those who reported that SNS were utilized at least half of the time while in these situations also reported experiencing a regrettable post. Most respondents indicated that they never used SNS after arguing with another(others), rarely after receiving bad news, and a little more frequently after receiving good news.

\section{Bivariate Analysis:}

One-way ANOVA tests show that there were no statistically significant differences in the proportion of regret reported at the categorical level for age, race, student status, or grade level. There was a statistically significant, with a $\mathrm{p}$ value of .004 , difference in the number of female respondents reporting regret versus males. There was a 12.1-point difference in the percentage of females reporting regret over the proportion of men who reported regret.

The proportion of individuals who responded that they had committed an SVP (as measured by reporting they had regretted something they had disclosed via social media) was compared between those belonging to the low and high-volume categories for each platform variable and the TEN. Statistically significant differences in the proportion of those reporting yes to regretting a social media post (indicating they had commit a SVP) was statistically significant at a $\mathrm{p}<.01$ and an alpha of .05 for all platforms and TEN. The proportion difference for users in the high-volume groups was higher by nearly 11 points in the Facebook group, 12.5 for 
Instagram, and roughly 14 for Twitter users. The proportion difference for TEN was 15 points higher for those in the high-volume group than the low volume group.

Only three of the eleven relationships provided a statistically significant difference in the proportion of individuals reporting regret. The presence of a teacher or professor and the presence of coworkers in an individual's network both provided statistically significant evidence with a $\mathrm{p}<.01$ that the proportion of individuals reporting regret was higher. The proportion of individuals reporting regret was statistically significantly higher for users with unknown people or strangers in their network with a $\mathrm{p}<.05$. The difference in reported regret was higher for both teacher/professor and co-workers by roughly thirteen points. While users reporting regret with strangers in their networks was higher by nine points when present.

The difference in proportions for the users in the low DON category was also statistically significantly different from the proportion of users in the high DON category for reported regret. With a $\mathrm{p}<.001$, users in the high-volume DON (reporting eight or more relationship types) was higher than the low DON category (seven or less relationships) by twenty points.

The proportion of users reporting regret was significantly higher with a $\mathrm{p}<.05$ by 8.5 points for high frequency Facebook users than low frequency users. High Frequency Twitter users had a higher proportion by twelve points over low frequency Twitter users with a $\mathrm{p}<.01$. The proportion of users who posted photos daily was higher by nearly 14 points over users who posted photos 4-6 times per week or less, which was statistically significant at a $p<.01$. Frequency of Instagram use or text-based posting on any platform had no statistically significant difference in their proportions of users who reported regret.

For both communication with friends and with family, there was a statistically significant difference in the proportions of those reporting regret between those in the low frequency and high frequency categories for these behaviors. The proportion of respondents in the high frequency category was higher by 7.67 points for communicating with friends and by 10.89 points for communicating with family at a $\mathrm{p}<.05$ and .01 respectively. The proportion of respondents who used SNS for work communications did not differ significantly between the low and high frequency of use groups. Additionally, there was no statistically significant difference between the proportions between those who used SNS for seeking employment opportunities between high and low frequency.

The liking of other's posts was a highly polarized variable, with individuals either responding they didn't engage in the behavior frequently, or they did engage in the behavior most of the time, with very few respondents indicating they did so at a moderate frequency. However, the proportion of individuals in the high frequency group was significantly higher than the low frequency group when reporting regret at a $\mathrm{p}<.001$. The high group was larger in proportion than the low frequency group by 14.15 points. Both proportions for the sharing of life events and recent activity were larger in the high frequency groups by roughly 12 points and significant at a $\mathrm{p}<.01$. The sharing of past activity also had a higher proportion of those who experienced regret in the high frequency group, which was larger by 9.61 points and significant at a $\mathrm{p}<.05$. 
The sharing of photos of one's self, family, and of friends all revealed significant differences in the proportion of respondents who had experienced regret between users in the low frequency and high frequency groups for each behavior. All three behaviors show that more individuals who engage in these behaviors at a high frequency reported regret than those who engaged in sharing photos at a low frequency. The difference was highest for photos of one's self at 16.32 points, followed by photos of friends at 13.86 points. Both were significant with $p$ values less than .001 . The sharing of family photos and regret was larger in the high frequency group by 11.5 points and significant at a $\mathrm{p}<.01$.

The sharing of both political and non-political opinions also provided a large statistically significant difference between those who engaged in the behaviors at low and high frequencies with $\mathrm{p}$ values less than .001 . Both behaviors trended towards low frequencies, however nearly $70 \%$ of respondents who engaged in either behavior reported experiencing regrettable posts. For non-political opinions the proportion reporting regret was larger by 19.79 for the high frequency group, while for political opinions the difference was 18.94 points in the same direction.

The sharing of information pertaining to affective states was also revealed to have significant differences in the proportions of reported regret between those who did so at low and high frequencies. While only half of those who engaged in these behaviors infrequently reported regret, approximately two thirds of those who shared their moods and feelings or vented frustration at least a moderate amount of time also reported sharing something via an SNS that they regretted. Both of these differences were significant at a $p$ value less than .001 with the high group for sharing moods/feelings being larger by 23.33 points and by 18.26 points for those who vented frustration frequently.

Individuals responded that they utilized SNS most of the time while alone, however SNS use in the presence of friends and family members was reduced dramatically. Significant differences in the proportions of the groups who engaged in SNS at low and high frequency and experienced a regrettable post were present. The proportion of those who frequently used SNS while alone was higher by 15.66 points and significant at a $p<.01$ over those who infrequently used SNS while alone. The proportions for those who utilized SNS with friends and those who did so with family present was higher by roughly 15 points and both were significant at a $\mathrm{p}<.001$.

Roughly $60 \%$ of respondents who utilized SNS frequently while at home reported posting something they regretted, which was 18.43 points higher and significant at a $p<.001$, than those who utilized SNS at home infrequently. The proportion of respondents who utilized SNS frequently at work reporting a regrettable post was higher by 12.55 points and significant at a $\mathrm{p}<.05$ compared to those who used SNS infrequently at work. While on vacation, those who used SNS frequently had a higher proportion of those who reported regret by 15.79 points, which was significant at a $\mathrm{p}<.001$.

There was a sizeable difference in the proportion of those who used SNS frequently and those who did so infrequently while on a date and reported a regrettable post, yet it was not statistically significant. However, the difference in proportions between high and low frequency 
SNS use at gatherings was significant at a $\mathrm{p}<.01$, and larger by 13.97 points for the high frequency use group.

The use of both drugs and alcohol provided statistically significant evidence of a difference in the proportion of those who reported regret at $p$ values less than .001 . The proportion for high frequency SNS use while drinking was higher than low frequency users by 16.58 points, while there was a difference for those using drugs of 17.57 points in the same direction.

The proportions of those who frequently use SNS after receiving good and bad news was significantly larger than those who infrequently did so by nearly 11 points for each type of news. This difference was significant at a $\mathrm{p}<.01$ for good news and a $\mathrm{p}<.05$ for bad news. The difference in proportions between low frequency use and high frequency use by those who had recently argued with others was 17.21 points in favor of high frequency use, and significant at a $\mathrm{p}<.001$.

\section{Multivariate Analysis:}

Utilizing a model building approach that reflected on the theoretical framework of this paper and evaluating the above relationships, multiple logistic models were developed that analyze the odds ratios for the dichotomous relationships between low value and high value groups for the variables of statistical and practical significance. All of the models include control variables of sex and concern for privacy. Sex was the only control variable to show statistically significant difference between response groups. Concern for privacy was controlled for through the use of a scale variable developed from four privacy oriented attitudinal measures. An index measure of willingness to disclose was also intended but failed to perform to an acceptable measure utilizing Cronbach's alpha (less than 0.80).

The first model utilizes the dichotomous variables measuring the total estimated network of SNS users and the diversity of relationships contained within those networks. This model was built on a sample of 609 respondents and returned a pseudo R squared of 0.032. Controlling for other model variables, SNS users with a total estimated network (TEN) greater than the mean TEN of 1479.45 are $64 \%$ more likely to commit an SVP on a SNS than those with a TEN less than the mean. This odds ratio was significant at a $\mathrm{p}<.01$. Similarly, SNS users with more than seven distinct relationships in their network were $77 \%$ more likely than those with seven or less relationships in network to commit SVP after controlling for the other model variables, which was significant at a $\mathrm{p}<.05$.

The second model analyzes the odds ratios of the dichotomized variables for frequency of use of the specific SNS and controlling for sex and privacy concern. The model returned a pseudo R squared value of 0.022 from a sample of 652. High frequency Facebook users were $23 \%$ more likely to commit SVP than low frequency users, while high frequency Instagram users were only $12 \%$ more likely, however neither of these odds ratios were statistically significant at an alpha of .05. Twitter users were statistically significantly more likely by $47 \%$ at a $\mathrm{p}<.05$ to commit SVP if they used the SNS frequently after controlling for other variables within the model. 
A third model utilizes behavioral variables for specific SNS uses that were identified as having statistically and practically significant differences between low and high frequency engagement in those behaviors. Similar to previous models, SNS user sex and concern for privacy is controlled within the model and returned a pseudo R squared of 0.076 from a sample of 649. SNS users who share photos of themselves at a high frequency were $50 \%$ more likely than those who engaged in the behavior at a low frequency, which was statistically significant at a $\mathrm{p}<.05$.

The sharing of personal opinions was not a statistically significant predictor of SVP at an alpha of .05, however, the sharing of political attitudes at a high frequency was. Those who frequently share political attitudes were $46 \%$ more likely to commit SVP than those who infrequently engaged in the behavior after controlling for other variables within the model. Further, the sharing of moods or feeling was not statistically significant in this model. Except, those who frequently vented frustration via SNS were $72 \%$ more likely to commit SVP than those who did so rarely. This was statistically significant at a $\mathrm{p}<.01$ after controlling for other model variables.

A model based on the situations in which people utilize SNS simultaneously was built from a sample of 645 and returned a pseudo R squared of .0461. Both the high frequency use of SNS while drinking and using drugs were statistically significant predictors of SVP at $p$ values less than .05 after controlling for other model variables. The high frequency use of SNS after arguing with others was a significant predictor of SVP at a $p<.01$. High frequency SNS users were $48 \%$ more likely than those who rarely used SNS while drinking, $66 \%$ more likely than low frequency SNS users who were also using drugs, and 63\% more likely than those who rarely use SNS after arguing with others after controlling for other model variables.

\section{Discussion:}

In general, for SNS users; large and diverse networks increased the likelihood of an individual reporting SVP. For nearly all of the variables measured in this study, more SNS users who had a high volume of network connections, above average number of distinct relationships in their network, frequently engaged in SNS use across a variety of behaviors, and did so frequently in social situations that influenced the ability to accurately perceive one's audience reported posting something they regretted than those who were grouped into the low category for these measures. Returning to Rubin's theoretical framework, these findings bring the process by which the routinization of media into clarity as a causal explanation for the over-disclosure of information that self-violates SNS user's privacy.

The reliance on schemas and stereotypes combined with the influence of salient figures and situations that interfere with audience perception appear to be influential factors leading to SNS user's self-violations of privacy. While one potential criticism of Wang et al.'s interview study of Facebook regret is that it relies on post facto recollection and rationalization of behaviors, by measuring behavior directly, this study serves to strengthen some of their findings, and to describe quantitatively the effect those findings have on a larger population of SNS users. 


\section{More Exclusive Networks:}

The first three hypotheses of this study focused on network complexity as measured by volume of network connections, diversity of relationships within networks and a potential synergistic interaction effect between the two. These findings demonstrated that both hypothesis one pertaining to network volume and hypothesis two concerning network diversity were supported that they were positively associated with self-violations of privacy as measured by the experience of regretting a SNS post. Hypothesis three, the presence of an interaction effect between the two network variables was not supported. As networks grow larger and more diverse, the process of accurately imagining one's actual audience, and matching that to corresponding socially appropriate disclosure of information becomes a task that is best suited to deliberate cognition. However, in the routinized process of social media consumption, this isn't the case and therefore a source of risk for SVP.

\section{Social Media Use:}

On the surface, general social media use has a positive association with SVP. From a simple opportunity standpoint, this seems common sense, that the more you post, the more opportunity that exists for information to be disclosed that one later regrets. However, when people are adept at a task, that simple opportunity is wiped away through skill at the task. Facebook and Instagram use show positive associations with SVP; however, they were not statistically significant predictors of the likelihood of SVP. Twitter was a significant predictor of SVP though, and this is likely due to limitations and formats of the specific SNS.

Facebook allows great freedom and depth of information to be shared, and users can clarify and explain their messages. Instagram often includes the use of filters, and other editing tasks prior to posting. Both of these platforms have a layer of checks and balances built in that partially buffer users from premature posting. Twitter, until recently, was limited to 140 characters, forcing users to compress their messages leaving opportunity for misinterpretations, explaining why Twitter users who did so daily were nearly $50 \%$ more likely to commit SVP than those who used it less frequently.

Similarly, with disclosure on SNS, the general use model for predicting the likelihood of SVP is very weak, only explaining about two percent of the variation within our sample. Hypothesis four is supported that specific social media use behaviors are positively associated with SVP and certain behaviors are significant predictors of SVP. The specific behaviors model allows a more in-depth analysis and understanding of specific forms of disclosure and a causal relationship with SVP. One of those specific behaviors, the sharing of photographs of one's self does match an opportunity explanation, however within the context of routinization, the act of posting self-photos provides a clearer picture of the process.

The selfie, is taken by an individual of themselves (and occasionally others), via a mobile device that is linked to SNS and generally, unless settings are adjusted, automatically uploaded to the SNS. An individual's focus is on their own image on the screen as it is being taken, and while they may reject images for their appearance, the salient concern is their own likeness and not background items or the surrounding information contained in the image. This extraneous 
information that others extract from images shared becomes a source of SVP that the sharer did not foresee or intend.

SNS users who engaged in the disclosure of highly personalized attitudes, particularly mood, feelings, personal opinions, and political opinions are significantly more likely to experience an SVP than those who engage in these behaviors infrequently. These behaviors appear to suffer from a false consensus effect, especially within the framework of routinization. As SNS users share their attitudinal dispositions, they fail to account for variation in attitudes amongst their audience, assuming that those they connect with are more similar than dissimilar. Political opinions in particular are highly contested in the current socio-political climate following the 2016 presidential election, leading to conflict when competing political attitudes become disclosed amongst network connections.

While moods and non-political opinions include mundane issues including emotional affect or a preference/dislike for pineapple on pizza, political stances have a more direct impact on social and economic outcomes for individuals leading them to have stronger attitudes and greater aversion to those being threatened by competing attitudes. This serves to explain why political attitudes significant predictors of SVP and other attitudinal disclosure behaviors were not.

\section{Risky Situations:}

While the venting of frustration via SNS is a behavior, it fits in line with other situations where SNS users are experiencing the phenomena Wang et al. described as "hot states". These are episodes of emotional turbulence, altering an individual's perceptions, goals, and ability to weigh the full consequences of one's actions. SNS users who used social media to vent their frustrations frequently were nearly $75 \%$ more likely than those who did so infrequently to commit a self-violation of privacy. Again, the affective hot state and relevant issue associated or causing that hot state becomes the salient focus of behavioral outcomes. SNS users who frequently vent frustrations via the media platform either perceive it as an appropriate function of the SNS or fail to concern themselves with the consequences of doing so. In either situation, the lack of concern or perception of it, lead SNS users to SVP.

The sharing of information after receiving good or bad news both appeared to be situations that could create a hot state leading SNS users to SVP. However, they were merely positively associated with SVP and were not statistically significant predictors. SNS use after arguing with others was statistically significant in predicting the likelihood of SVP though. While elation or sadness from receiving specific types of information that SNS users may wish to re-share were not sufficient in explaining SVP, the arousal from conflict and confrontation with others did serve to predict SVP.

This potentially arises from a need to marshal support from one's network, defend one's own standpoint, or seek affirmation in one's attitudes and opinions. Again, the combination of a false consensus effect and a hot state confound the process of disclosure, leading to a mismatch of intended and actual audience, information one seeks to disclose and that which actually is shared, and a failure to separate intended from unintended consequences. Regardless, hypothesis 
five is supported that "hot states" are positively associated with SVP, and specific "hot states" are significant predictors of SVP.

While Wang et al. uncovered the concept of "hot states" in relation to over-disclosure and regret, this study also provides evidence for an intoxicated effect, or situations in which cognitive ability is depressed, particularly from the consumption of alcohol and drugs. Alcohol is a central nervous system depressant, and impairs cognitive ability leading to among other issues an inability to fully perceive one's surroundings, consequences for behavior, and perceptions of those they interact with (Moewaka Barnes et al. 2016; Rabow, Neuman, and Hernandez 1987). Similarly, a variety of schedule one narcotics including marijuana, ecstasy, cocaine, and opioids have similar effects on the human body and mind.

SNS users who engaged in heavy social media use during cold states, while under the influence of alcohol were nearly 50\% more likely to commit an SVP than those who did not use social media use while under the influence of alcohol while similarly, SNS users were two thirds more likely to commit SVP if frequently using SNS while using drugs. Hypothesis six was clearly supported and is an easily avoidable source of SVP.

\section{Conclusion:}

Wang et al. took an important first step in identifying the ways and potential reasons that people share too much information. Building from a standpoint that SNS users want to avoid SVP, especially those of information, attitudes, and behaviors that lead to the more severe formal consequences of economic loss and criminal charges. By further expanding on the relationships of specific factors, effective strategies can be promoted to assist SNS users from over-disclosure and creating a healthier SNS atmosphere and culture.

But does that necessarily mean the SNS users should limit their network's in order to avoid SVP? Most likely no, as most SNS offer various privacy settings that allow users to control the flow of their information to intended audiences. What SNS users need to do to avoid SVP is to develop strong awareness of their networks, through cultivation and familiarization as opposed to limitation, so that even though SNS media consumption is routinized it is built on stronger and more accurate schemas representing their audiences. This is a strategy that appears to be utilized by many of those who reported regret within the sample. The removal of inactive ties was an exercise in network familiarization and functioned to keep networks known and manageable.

Further, by identifying the specific behaviors that SNS users engage in which most highly predict the likelihood of SVP, best practices for those who wish to engage in them can be promoted. Pushing SNS users to adjust their automated processes linked to the sharing of "selfies", promoting civil discourse of political positions, and

As a society, there exists a message of avoiding specific behaviors while under the influence of drugs and/or alcohol. Specifically, a campaign against drunk driving has been in effect since the late half of the $20^{\text {th }}$ century. Further, this has been expanded to include other 
distractions and states where ability to function is impaired, including texting, lack of sleep, and physical/mental health impairments. We don't encourage people to become better drunk drivers, encourage the ability to text and drive, or leave the judgement of acceptable risk up to drivers who haven't slept for an extended period of time. In order to avoid SVP due to hot or cold states, the only $100 \%$ effective strategy is SNS abstinence.

Social media and SNS have a multitude of positive applications that enable people to connect, solve problems, and increase quality of life. However, like nearly any technological innovation, SNS carry with them inherent risks if not afforded the level of respect and diligence in utilizing any tool. Further, as SNS continue to grow and "advance" the trend towards ease of use and access reinforces the routinization of its own consumption. The need for purposeful posting and deliberate disclosure needs to be weighed against the potential consequences of SVP and poor impression management. If you don't believe me, just go ask Justine Sacco. 


\section{References}

Anon. 2013. “How Diverse Is West Virginia University?" College Factual. Retrieved April 16, 2018 (https://www.collegefactual.com/colleges/west-virginia-university/student-life/diversity/).

Bareket-Bojmel, Liad, Simone Moran, and Golan Shahar. 2016. "Strategic Self-Presentation on Facebook: Personal Motives and Audience Response to Online Behavior." Computers in Human Behavior 55:788-95.

Bazarova, Natalya N. and Yoon Hyung Choi. 2014. "Self-Disclosure in Social Media: Extending the Functional Approach to Disclosure Motivations and Characteristics on Social Network Sites." Journal of Communication 64(4):635-57.

Bernstein, Michael S., Eytan Bakshy, Moira Burke, and Brian Karrer. 2013. "Quantifying the Invisible Audience in Social Networks." Pp. 21-30 in Proceedings of the SIGCHI Conference on Human Factors in Computing Systems. ACM. Retrieved March 17, 2017 (http://dl.acm.org/citation.cfm?id=2470658).

Brake, David R. 2009. "'As If Nobody's Reading'?: The Imagined Audience and Socio-Technical Biases in Personal Blogging Practice in the UK." London School of Economics. Retrieved March 1, 2017 (https://www.researchgate.net/profile/David_R_Brake/publication/40888101_As_if_nobodys_r eading_the_imagined_audience_and_sociotechnical_biases_in_personal_blogging_practice_in_the_UK/links/00b7d53199c859b063000000 .pdf).

Buchanan, Tom, Carina Paine, Adam N. Joinson, and Ulf-Dietrich Reips. 2007. "Development of Measures of Online Privacy Concern and Protection for Use on the Internet." Journal of the American Society for Information Science and Technology 58(2):157-65.

Case, Philippa, Paul Sparks, and Louisa Pavey. 2016. "Identity Appropriateness and the Structure of the Theory of Planned Behaviour." British Journal of Social Psychology 55(1):109-25.

Custers, Bart, Simone van der Hof, and Bart Schermer. 2014. "Privacy Expectations of Social Media Users: The Role of Informed Consent in Privacy Policies." Policy \& Internet 6(3):268-295.

Debatin, Bernhard, Jennette P. Lovejoy, Ann-Kathrin Horn, and Brittany N. Hughes. 2009. "Facebook and Online Privacy: Attitudes, Behaviors, and Unintended Consequences." Journal of ComputerMediated Communication 15(1):83-108.

Derlega, Valerian J. and Alan L. Chaikin. 1977. "Privacy and Self-Disclosure in Social Relationships." Journal of Social Issues 33(3).

Doster, Leigh. 2013. "Millennial Teens Design and Redesign Themselves in Online Social Networks: Mill. Teens De/redesign Selves in OSNs." Journal of Consumer Behaviour 12(4):267-79.

Everett, Catherine. 2010. “Social Media: Opportunity or Risk?” Computer Fraud \& Security 2010(6):8-10.

de Hooge, llona E., Marcel Zeelenberg, and Seger M. Breugelmans. 2011. "A Functionalist Account of Shame-Induced Behaviour." Cognition \& Emotion 25(5):939-46. 
Joinson, Adam, Ulf-Dietrich Reips, Tom Buchanan, and Carina B.Paine Schofield. 2010. "Privacy, Trust, and Self-Disclosure Online." Human-Computer Interaction 25(1):1-24.

Kim, Jinsuk and Kathryn Dindia. 2011. "Online Self-Disclosure: A Review of Research." ComputerMediated Communication in Personal Relationships 156-180.

Litt, Eden. 2012. “Knock, Knock. Who's There? The Imagined Audience." Journal of Broadcasting \& Electronic Media 56(3):330-45.

Mesch, Gustavo S. and Guy Beker. 2010. "Are Norms of Disclosure of Online and Offline Personal Information Associated with the Disclosure of Personal Information Online?" Human Communication Research 36(4):570-92.

Moewaka Barnes, Helen et al. 2016. "Alcohol and Social Media: Drinking and Drunkenness While Online." Critical Public Health 26(1):62-76.

Norberg, Patricia A. and Daniel R. Horne. 2007. "Privacy Attitudes and Privacy-Related Behavior." Psychology \& Marketing 24(10):829-47.

Oolo, Egle and Andra Siibak. 2013. "Performing for One's Imagined Audience: Social Steganography and Other Privacy Strategies of Estonian Teens on Networked Publics." Cyberpsychology: Journal of Psychosocial Research on Cyberspace 7(1). Retrieved November 9, 2016 (http://www.cyberpsychology.eu/view.php?cisloclanku=2013011501\&article=7).

Rabow, Jerome, Carole A. Neuman, and Anthony C. R. Hernandez. 1987. "Contingent Consistency in Attitudes, Social Support and the Consumption of Alcohol: Additive and Interactive Effects." Social Psychology Quarterly 50(1):56.

Ronson, Jon. 2015. "How One Stupid Tweet Blew Up Justine Sacco's Life." The New York Times, February 12. Retrieved April 16, 2018 (https://www.nytimes.com/2015/02/15/magazine/how-one-stupidtweet-ruined-justine-saccos-life.html).

Taddicken, Monika. 2014. “The 'Privacy Paradox' in the Social Web: The Impact of Privacy Concerns, Individual Characteristics, and the Perceived Social Relevance on Different Forms of SelfDisclosure." Journal of Computer-Mediated Communication 19(2):248-73.

Tufekci, Z. 2007. "Can You See Me Now? Audience and Disclosure Regulation in Online Social Network Sites." Bulletin of Science, Technology \& Society 28(1):20-36.

Wang, Yang et al. 2011. "I Regretted the Minute I Pressed Share: A Qualitative Study of Regrets on Facebook." P. 10 in Proceedings of the Seventh Symposium on Usable Privacy and Security. ACM. Retrieved March 17, 2017 (http://dl.acm.org/citation.cfm?id=2078841).

Zhou, Lu, Wenbo Wang, and Keke Chen. 2016. "Tweet Properly: Analyzing Deleted Tweets to Understand and Identify Regrettable Ones." Pp. 603-12 in. ACM Press. Retrieved March 17, 2017 (http://dl.acm.org/citation.cfm?doid=2872427.2883052). 


\section{Appendix A: Results Tables}

Table R1: Sample Demographics

\begin{tabular}{|c|c|}
\hline $\begin{array}{l}\text { Table R1: Sample } \\
\text { Demographics }\end{array}$ & $N=658$ \\
\hline Age & $\begin{array}{l}\text { Range:18-23 } \\
\text { Mean: } 19.9 y r s \\
\text { SD: } 1.4\end{array}$ \\
\hline $\begin{array}{cl}\text { Sex } & \\
- & \text { Female } \\
- & \text { Male } \\
\end{array}$ & $\begin{array}{l}69.3 \%(456) \\
30.7 \%(202) \\
\end{array}$ \\
\hline $\begin{array}{cl}\text { Race } & \\
- & \text { White } \\
- & \text { Black } \\
- & \text { Latino } \\
- & \text { Asian } \\
- & \text { Other } \\
\end{array}$ & $\begin{array}{l}87.08 \%(573) \\
2.89 \%(19) \\
2.89 \%(19) \\
4.26 \%(28) \\
2.89 \%(19) \\
\end{array}$ \\
\hline \begin{tabular}{cc}
\multicolumn{2}{c}{ Student status } \\
$-\quad$ Full time \\
$-\quad$ Part time
\end{tabular} & $\begin{array}{l}97.26 \%(640) \\
1.98 \%(13)\end{array}$ \\
\hline \begin{tabular}{cl}
\multicolumn{2}{l}{ Grade level } \\
- & Freshman \\
- & Sophomore \\
- & Junior \\
- & Senior \\
- & Other
\end{tabular} & $\begin{array}{l}29.79 \%(196) \\
23.40 \%(154) \\
18.24 \%(120) \\
19.15 \%(126) \\
9.27 \%(61)\end{array}$ \\
\hline
\end{tabular}


Table R2: Reported Regret by Demographics

\begin{tabular}{|c|c|c|c|}
\hline $\begin{array}{l}\text { Table R2: Reported Regret } \\
\text { by Demographics }\end{array}$ & $\mathbf{N}$ & Number Responding Yes & Proportion \\
\hline Age & 658 & 372 & 56.53 \\
\hline-18 & 124 & 64 & 51.61 \\
\hline-19 & 173 & 98 & 56.65 \\
\hline-20 & 145 & 79 & 54.48 \\
\hline$-\quad 21$ & 101 & 65 & 64.36 \\
\hline$-\quad 22$ & 75 & 39 & 52.00 \\
\hline$-\quad 23$ & 40 & 27 & 67.50 \\
\hline Sex $^{1}$ & 658 & 372 & 56.53 \\
\hline - Female & 456 & 275 & 60.31 \\
\hline - Male & 202 & 97 & 48.02 \\
\hline Race & 658 & 372 & 56.53 \\
\hline - White & 573 & 324 & 56.54 \\
\hline - $\quad$ Black & 19 & 11 & 57.89 \\
\hline - Latino & 19 & 10 & 52.63 \\
\hline - Asian & 28 & 13 & 46.43 \\
\hline - Other & 19 & 14 & 73.68 \\
\hline Student Status & 653 & 368 & 56.36 \\
\hline - $\quad$ Full time & 640 & 360 & 56.25 \\
\hline - $\quad$ Part time & 13 & 8 & 61.54 \\
\hline Grade Level & 657 & 372 & 56.62 \\
\hline - Freshmen & 196 & 104 & 53.06 \\
\hline - Sophomore & 154 & 88 & 57.14 \\
\hline - Junior & 120 & 65 & 54.17 \\
\hline - Senior & 126 & 78 & 61.90 \\
\hline - Other & 61 & 37 & 60.66 \\
\hline
\end{tabular}

${ }^{1}$ Difference in proportion of reported regret by sex significant at $p<.01$. 
Table R3: Reported Regret for Network Complexity between High and Low Variable Groupings:

\begin{tabular}{|c|c|c|c|c|c|}
\hline Network Volume and Diversity & Mean & SD & Low Group ${ }^{1}$ & High Group ${ }^{2}$ & Difference $^{3}$ \\
\hline $\begin{array}{ll}\text { Network Volume } \\
- & \text { Facebook }(n=640) \\
- & \text { Instagram }(n=644) \\
- & \text { Twitter }(n=624) \\
\end{array}$ & $\begin{array}{l}575.17 \\
630.00 \\
418.68\end{array}$ & $\begin{array}{c}1368.41 \\
625.65 \\
2533.78\end{array}$ & $\begin{array}{l}53.56 \\
52.64 \\
53.87\end{array}$ & $\begin{array}{l}64.39 \\
65.07 \\
68.12\end{array}$ & $\begin{array}{l}10.83^{* *} \\
12.43^{* *} \\
14.25^{* *}\end{array}$ \\
\hline $\begin{array}{l}\text { Total Estimated Network (TEN) } \\
(n=611)\end{array}$ & 1479.45 & 1341.03 & 50.33 & 65.37 & $15.04^{* * *}$ \\
\hline Network Diversity $(n=658)$ & N present & $\begin{array}{c}\text { Proportion } \\
\text { present }\end{array}$ & $\begin{array}{l}\text { Regret if } \\
\text { absent }\end{array}$ & $\begin{array}{l}\text { Regret if } \\
\text { present }\end{array}$ & \\
\hline $\begin{array}{ll}\text { - } & \text { Partner/Spouse } \\
\text { - } & \text { Friend } \\
\text { - } & \text { Acquaintance } \\
\text { - } & \text { Family } \\
\text { - } & \text { Classmate } \\
\text { - } & \text { Teacher/Professor } \\
\text { - } & \text { Co-Worker } \\
\text { - } & \text { Boss/Employer } \\
\text { - } & \text { Potential Employer } \\
\text { - } & \text { Unknown/Strangers } \\
\text { - } & \text { Other }\end{array}$ & $\begin{array}{c}560 \\
649 \\
597 \\
633 \\
629 \\
447 \\
512 \\
297 \\
161 \\
202 \\
3\end{array}$ & $\begin{array}{c}85.10 \\
98.63 \\
90.72 \\
96.20 \\
95.59 \\
67.93 \\
77.81 \\
45.13 \\
24.47 \\
30.69 \\
0.45\end{array}$ & $\begin{array}{c}52.04(51) \\
55.56(5) \\
45.90(28) \\
48.00(12) \\
44.83(13) \\
47.39(100) \\
46.58(68) \\
55.96(202) \\
56.94(283) \\
53.73(245) \\
56.49(370)\end{array}$ & $\begin{array}{l}57.32(321) \\
56.55(367) \\
57.62(344) \\
56.87(360) \\
57.07(359) \\
60.85(272) \\
59.38(304) \\
57.24(170) \\
55.28(89) \\
62.87(127) \\
66.67(2)\end{array}$ & $\begin{array}{c}5.28 \\
0.99 \\
11.72 \\
8.87 \\
12.24 \\
13.46^{* *} \\
12.80^{* *} \\
1.28 \\
1.66 \\
9.14^{*} \\
10.18\end{array}$ \\
\hline & Mean & SD & Regret Low $^{1}$ & Regret High² & \\
\hline $\begin{array}{l}\text { Diversity of Network (DON) } \\
\text { - Aggregate of Relationships } \\
\text { present in network }\end{array}$ & 7.13 & 1.82 & $39.62(42)$ & $59.78(330)$ & $20.16^{* * *}$ \\
\hline $\begin{array}{l}\text { Network Awareness } \\
-\quad \text { Remove inactive ties } \\
(n=656)\end{array}$ & $\begin{array}{c}\text { No } \\
20.58(135)\end{array}$ & $\begin{array}{c}\text { Yes } \\
79.42(521)\end{array}$ & $45.19(61)$ & $59.50(310)$ & $14.31^{* *}$ \\
\hline
\end{tabular}

${ }^{1}$ Proportion at or below mean of variable reporting regret.

${ }^{2}$ Proportion above mean of variable reporting regret.

${ }^{3}$ Absolute value of difference of reported regret between low/high groups for each variable.

${ }^{*} \mathrm{p}<.05, * * \mathrm{p}<.01, * * * \mathrm{p}<.001$ 
Table R4: Reported Regret by High and Low Frequency Use and Behavior Groups:

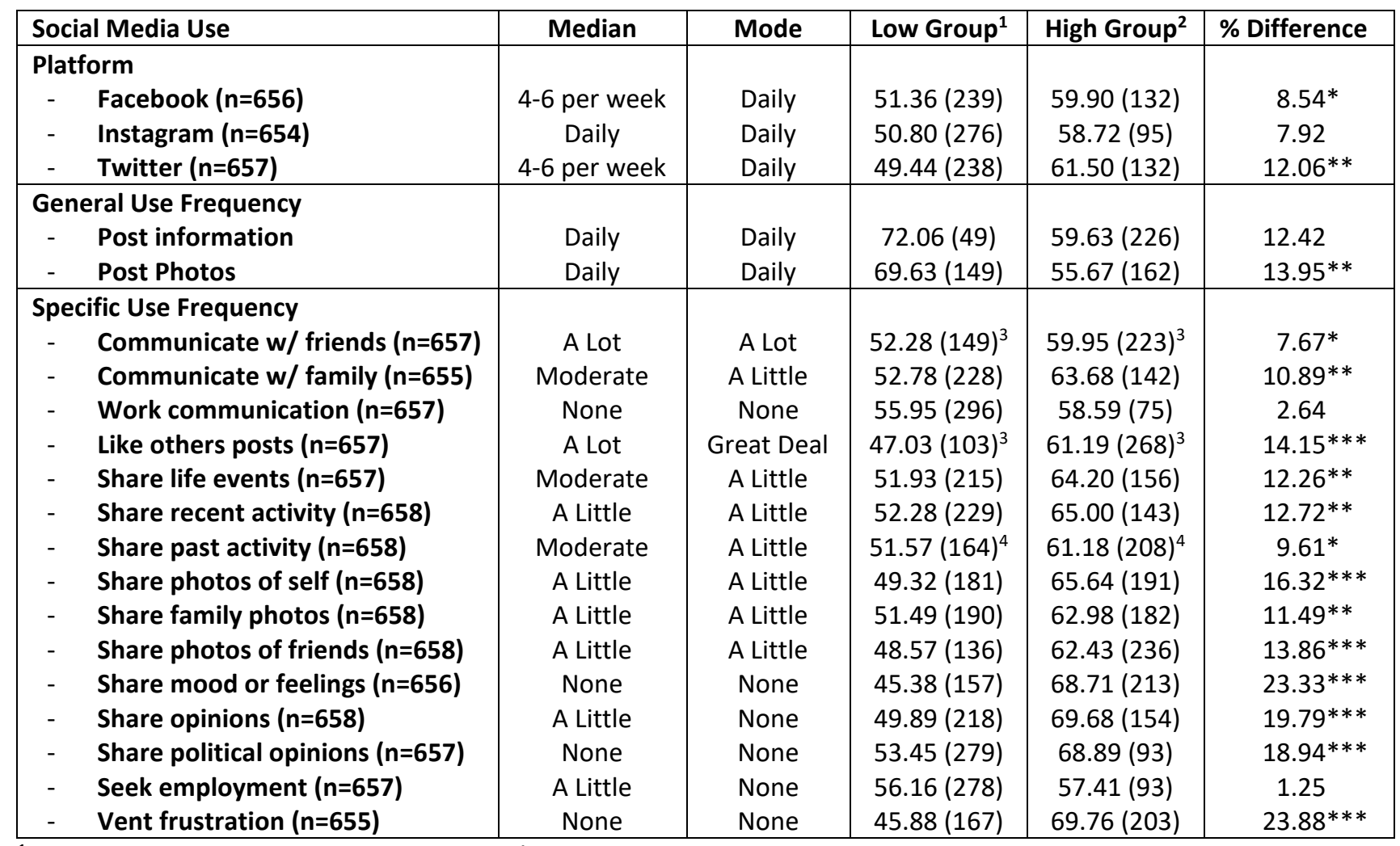

${ }^{1}$ Proportion (count) at or below median/mean of variable reporting regret and.

${ }^{2}$ Proportion (count) above median/mean of variable reporting regret and.

${ }^{3}$ Low category at moderate or lower frequency, high category at a lot or greater frequency.

${ }^{4}$ Low category below median response, high category at or above median response.

${ }^{*} \mathrm{p}<.05, * * p<.01, * * * \mathrm{p}<.001$ 
Table R5: Reported Regret by High and Low Frequency SNS Use Groups in Situations:

\begin{tabular}{|c|c|c|c|c|c|}
\hline Concurrent Situations & Median & Mode & $\begin{array}{l}\text { Regret } \\
\text { Low }^{1}\end{array}$ & $\begin{array}{l}\text { Regret } \\
\text { High }^{2}\end{array}$ & \% Difference \\
\hline \multicolumn{6}{|l|}{ Use Frequency in Situation } \\
\hline - $\quad$ Alone $(n=655)$ & Most of time & Most of time & $43.30(42)$ & $58.96(329)$ & $15.66^{* *}$ \\
\hline With family ( $n=656)$ & Sometimes & Sometimes & $52.06(240)$ & $67.18(131)$ & \\
\hline With Friends $(n=655)$ & Somet & Sometimes & $51.36(224)$ & $66.67(146)$ & $15.29 * * *$ \\
\hline - At work (n=653) & Sometimes & Sometimes & $54.39(291)$ & $66.95(79)$ & $12.55^{*}$ \\
\hline At home ( $n=656)$ & Most of time & Most of time & $41.38(48)$ & $59.81(323)$ & $18.43 * * *$ \\
\hline On vacation $(n=656)$ & Sometimes & Sometimes & $50.13(193)$ & $65.93(178)$ & $15.79 * * *$ \\
\hline On a date $(n=654)$ & Sometimes & Sometimes & $55.52(337)$ & $68.09(32)$ & 12.56 \\
\hline At a gathering $(n=656)$ & Sometimes & Sometimes & $53.36(270)$ & $67.33(101)$ & $13.97^{* *}$ \\
\hline While drinking alcohol $(n=656)$ & Sometimes & Never & $50.82(218)$ & $67.40(153)$ & $16.58^{* * *}$ \\
\hline While using drugs $(n=650)$ & Never & Never & $51.82(242)$ & $69.40(127)$ & $17.57 * * *$ \\
\hline After arguing $w /$ others $(n=654)$ & Never & Never & $48.02(158)$ & $65.23(212)$ & $17.21^{* * *}$ \\
\hline After getting good news ( $n=655)$ & Half the time & Sometimes & $50.93(164)$ & $61.86(206)$ & $10.93^{* *}$ \\
\hline After getting bad news ( $n=655$ ) & Sometimes & Sometimes & $53.81(261)$ & $64.71(110)$ & $10.89 *$ \\
\hline
\end{tabular}

${ }^{1}$ Proportion (count) use in situation at less than half of the time reporting regret.

${ }^{2}$ Proportion (count) use in situation at least half of the time reporting regret.

$* \mathrm{p}<.05, * * \mathrm{p}<.01, * * * \mathrm{p}<.001$

Table R6: Logistic Regression Models for Self-Violation of Privacy

\begin{tabular}{|c|c|c|c|c|c|}
\hline Variable $^{1} \quad$ Model & $\begin{array}{l}\text { Network } \\
\text { Complexity }\end{array}$ & Use Model & $\begin{array}{c}\text { Behavior } \\
\text { Model }\end{array}$ & $\begin{array}{l}\text { Situational } \\
\text { Model }\end{array}$ & Combined Model \\
\hline Sex=Male & $0.73(0.14)$ & $0.68(0.12)^{*}$ & $0.71(0.13)$ & $0.66(0.12)^{*}$ & $0.88(0.18)$ \\
\hline Privacy & $0.76(0.13)$ & $0.79(0.13)$ & $0.87(0.14)$ & $0.96(0.16)$ & $0.90(0.16)$ \\
\hline TEN & $1.64(0.28)^{* *}$ & & & & $1.28(0.26)$ \\
\hline DON & $1.77(0.42)^{*}$ & & & & $1.65(0.41)^{*}$ \\
\hline Facebook use & & $1.23(0.21)$ & & & $1.12(0.22)$ \\
\hline Twitter use & & $1.47(0.25)^{*}$ & & & $0.94(0.19)$ \\
\hline Instagram use & & $1.12(0.21)$ & & & $1.12(0.24)$ \\
\hline Share self-photos & & & $1.50(0.27)^{*}$ & & $1.31(0.26)$ \\
\hline Share mood/feelings & & & $1.36(0.28)$ & & $1.27(0.28)$ \\
\hline Share opinions & & & $1.32(0.28)$ & & $1.15(0.26)$ \\
\hline Share political views & & & $1.46(0.28)^{*}$ & & $1.38(0.28)$ \\
\hline Vent Frustration & & & $1.72(0.36)^{* *}$ & & $1.67(0.38)^{*}$ \\
\hline Drinking alcohol & & & & $1.48(0.27)^{*}$ & $1.20(0.25)$ \\
\hline Using Drugs & & & & $1.66(0.34)^{*}$ & $1.13(0.26)$ \\
\hline After arguing & & & & $1.63(0.29)^{* *}$ & $1.37(0.27)$ \\
\hline Constant & $0.84(0.21)$ & $1.08(0.23)$ & $0.71(0.13)$ & $0.92(0.16)$ & $0.33(0.11)^{* * *}$ \\
\hline Pseudo R2 & 0.032 & 0.022 & 0.076 & 0.046 & 0.091 \\
\hline $\mathbf{N}=$ & 609 & 652 & 649 & 645 & 595 \\
\hline
\end{tabular}

${ }^{1}$ Variables coded as High=1 unless noted.

Odds Ratios (Robust Standard Errors)

${ }^{*} p<.05, * * p<.01, * * * p<.001$ 


\section{Appendix B: Survey}

\section{Self-violations of privacy}

Welcome to the research study!

We are interested in understanding social media use and privacy concerns. You will be presented with information relevant to social media use and asked to answer some questions about it. Please be assured that your responses will be kept completely confidential. WVU IRB approval is on file and accessible through the WVU Office of Research Integrity \& Compliance.

The study should take you around 10 minutes to complete. Your participation in this research is voluntary. You have the right to withdraw at any point during the study, for any reason, and without any prejudice. If you would like to contact the Principal Investigator in the study to discuss this research, please e-mail Matthew Hartwell via MPH0011@mix.wvu.edu.

By clicking the button below, you acknowledge that your participation in the study is voluntary, you are 18 years of age, and that you are aware that you may choose to terminate your participation in the study at any time and for any reason.

Please note that this survey will be best displayed on a laptop or desktop computer. Some features may be less compatible for use on a mobile device.

I agree, begin the study (1)

I do not agree, I do not wish to participate (2) 
Q2 What is your biological sex?

Male (1)

Female (2)

Q3 Choose one or more races that you consider yourself to be:

White (1)

Black or African American (2)

Hispanic/Latino (7)

Asian (4)

American Indian or Alaska Native (3)

Native Hawaiian or Pacific Islander (5)

Other (specify) (6) 
Q4 What is your current student status?

Full Time (1)

Part Time (2)

Q5 What is your current year in college?

Freshman (1)

Sophomore (2)

Junior (3)

Senior (4)

Other (Please explain) (5)

Q6 Are you involved in any student organizations on campus? Check all that apply.

Fraternity/Sorority (1)

Collegiate Sports (2)

Intramural Sports (3)

Student Government (4)

Student Clubs or Groups (5)

Other (Please Specify) (6) 
Q7 Please indicate to what extent the following statements about sharing information describe you.

$\mid \begin{array}{ccccc}\text { Does not } & \text { Describes me } \\ \text { describe me } & \text { slightly well } & \begin{array}{c}\text { Describes me } \\ \text { moderately }\end{array} & \begin{array}{c}\text { Describes me } \\ \text { very well (4) }\end{array} & \begin{array}{c}\text { Describes me } \\ \text { extremely well }\end{array} \\ (1) & (2) & \text { well (3) } & \text { (5) }\end{array}$

I prefer that
people know
only a little bit
about me. (1)
I sometimes
find myself
telling casual
acquaintances
things about
myself. (2)
There are
many things
about myself
that I would
rather not talk
about with
people. (3)


Q8 Please indicate to what extent the following statements about privacy and security describe you.

$\mid \begin{array}{ccccc}\text { Does not } & \text { Describes me } \\ \text { describe me } & \text { slightly well } & \begin{array}{c}\text { Describes me } \\ \text { moderately }\end{array} & \begin{array}{c}\text { Describes me } \\ \text { very well (4) }\end{array} & \begin{array}{c}\text { Describes me } \\ \text { extremely well }\end{array} \\ (1) & (2) & \text { well (3) } & & \text { (5) }\end{array}$

In general, I
am concerned
about my
privacy while
using the
internet. (1)
I am
concerned
about online
identity theft.
(2)
I am
concerned
about people
online not
being who
they say they
are. (3)
I am
concerned
about people I
do not know
obtaining
personal
information
about my
online
activities. (4)


Q9 Please indicate how often you use the following social media platforms.

\begin{tabular}{c|ccccc} 
& Daily (21) & $\begin{array}{c}\text { 4-6 times a } \\
\text { week (22) }\end{array}$ & $\begin{array}{c}\text { 2-3 times a } \\
\text { week (23) }\end{array}$ & $\begin{array}{c}\text { Once a week } \\
\text { (24) }\end{array}$ & Never (25) \\
\hline Facebook (1) & & & & \\
Instagram (2) & & & &
\end{tabular}

Q10 How often do you post Facebook status updates, Tweet, or post to Instagram?

\begin{tabular}{c|ccccc} 
& Daily (1) & $\begin{array}{c}4-6 \text { times a } \\
\text { week (2) }\end{array}$ & $\begin{array}{c}2-3 \text { times a } \\
\text { week (3) }\end{array}$ & $\begin{array}{c}\text { Once a week } \\
\text { (4) }\end{array}$ & Never (5) \\
\hline $\begin{array}{c}\text { (Facebook, } \\
\text { Instagram, } \\
\text { and/or }\end{array}$ & & & \\
Twitter) (1) & & & &
\end{tabular}

Q11 How often do you post images of yourself on social media?

\begin{tabular}{c|ccccc} 
& Daily (1) & $\begin{array}{c}4-6 \text { times a } \\
\text { week (2) }\end{array}$ & $\begin{array}{c}\text { 2-3 times a } \\
\text { week (3) }\end{array}$ & $\begin{array}{c}\text { Once a week } \\
(4)\end{array}$ & Never (5) \\
\hline $\begin{array}{c}\text { (Facebook, } \\
\text { Instagram, } \\
\text { and/or } \\
\text { Twitter) (1) }\end{array}$ & & & & \\
\hline
\end{tabular}

Q12 Approximately how soon after an event or activity do you share pictures from that event/activity on social media? Please indicate the number of hours, use 0 for during or immediately following. 
Q13 Please indicate to what extent you use social media for the following reasons. 


\begin{tabular}{|c|c|c|c|c|c|}
\hline & None at all (1) & A little (2) & $\begin{array}{l}\text { A moderate } \\
\text { amount (3) }\end{array}$ & $A$ lot (4) & $\begin{array}{l}\text { A great deal } \\
\text { (5) }\end{array}$ \\
\hline $\begin{array}{l}\text { Communicate } \\
\text { directly with } \\
\text { friend(s): (1) }\end{array}$ & $\bigcirc$ & & & & D \\
\hline $\begin{array}{l}\text { Communicate } \\
\text { directly with } \\
\text { family: (2) }\end{array}$ & & & & & \\
\hline $\begin{array}{l}\text { Communicate } \\
\text { with co-workers } \\
\text { about work } \\
\text { related issues: } \\
\text { (3) }\end{array}$ & & & & & \\
\hline $\begin{array}{l}\text { Like other posts: } \\
\text { (4) }\end{array}$ & C & & & & P \\
\hline $\begin{array}{l}\text { Share life events } \\
\text { (birthdays, } \\
\text { anniversaries, } \\
\text { births/deaths): } \\
\text { (5) }\end{array}$ & ( & & & & \\
\hline $\begin{array}{l}\text { Share recent } \\
\text { activity within 1- } \\
2 \text { hours: }(6)\end{array}$ & & & & & \\
\hline $\begin{array}{c}\text { Share past } \\
\text { activity older } \\
\text { than } 2 \text { hours: (7) }\end{array}$ & & & & & \\
\hline Share selfies: (8) & ( & & & & \\
\hline $\begin{array}{c}\text { Share } \\
\text { photographs of } \\
\text { family: (9) }\end{array}$ & & & & & \\
\hline $\begin{array}{c}\text { Share } \\
\text { photographs of } \\
\text { friends: (10) }\end{array}$ & & & & & \\
\hline $\begin{array}{l}\text { Share feelings or } \\
\text { mood: (11) }\end{array}$ & 0 & & $\Omega$ & & $\bigcirc$ \\
\hline
\end{tabular}




Express non-
political
personal
opinions: (12)
Express
personal
political
opinions: (13)
Seek out job
opportunities:
(14)
Express
frustration/vent:
(15)

(15)

Q14 For each platform please give an approximate value for total number of Friends/Contacts/Followers:

\begin{tabular}{c|c}
\hline Facebook (1) & Number of Friends/Contacts/Followers. (1) \\
\hline Instagram (2) & \\
\hline Twitter (3) & \\
\hline
\end{tabular}


Q15 Who have you accepted friend requests from?

\begin{tabular}{|c|c|}
\hline & Check all that apply. (1) \\
\hline \multicolumn{2}{|c|}{ Partner/Spouse/Significant Other (1) } \\
\hline \multicolumn{2}{|l|}{ Friends (2) } \\
\hline \multicolumn{2}{|c|}{ Acquaintances (i.e. Friend of a Friend) (3) } \\
\hline \multicolumn{2}{|l|}{ Family Member (4) } \\
\hline \multicolumn{2}{|l|}{ Classmate (Current or Former) (5) } \\
\hline \multicolumn{2}{|c|}{ Teachers/Professors (Current or Former) (6) } \\
\hline \multicolumn{2}{|c|}{$\begin{array}{l}\text { Co-Workers/Colleagues/Clients (Current or } \\
\text { Former) (7) }\end{array}$} \\
\hline \multicolumn{2}{|c|}{ Boss/Manager (Current or Former) (8) } \\
\hline \multicolumn{2}{|c|}{$\begin{array}{l}\text { Potential Employers/Recruiters (Current or } \\
\qquad \text { Former) (9) }\end{array}$} \\
\hline \multicolumn{2}{|l|}{ People you don't know (10) } \\
\hline Other (Please explain) (11) & \\
\hline
\end{tabular}


Q16 How often do you remove friends/followers that you consider inactive?

\begin{tabular}{l|lccc} 
Never (1) & Sometimes (2) & $\begin{array}{c}\text { About half the } \\
\text { time (3) }\end{array}$ & $\begin{array}{c}\text { Most of the } \\
\text { time (4) }\end{array}$ & Always (5) \\
$\begin{array}{c}\text { (Facebook, } \\
\text { Instagram, } \\
\text { and/or } \\
\text { Twitter) (1) }\end{array}$ & & & \\
\end{tabular}

Q17 How often do you use social media in the following situations (Facebook, Instagram, or Twitter only)? 


\begin{tabular}{|c|c|c|c|c|c|}
\hline & Never (1) & Sometimes (2) & $\begin{array}{c}\text { About half the } \\
\text { time (3) }\end{array}$ & $\begin{array}{c}\text { Most of the } \\
\text { time (4) }\end{array}$ & Always (5) \\
\hline $\begin{array}{l}\text { While alone } \\
\text { (1) }\end{array}$ & & & & & 0 \\
\hline $\begin{array}{l}\text { While } \\
\text { spending time } \\
\text { with family (2) }\end{array}$ & & & & & $\bigcirc$ \\
\hline $\begin{array}{l}\text { While } \\
\text { spending time } \\
\text { with friends } \\
\text { (3) }\end{array}$ & & & & & 0 \\
\hline $\begin{array}{l}\text { While at work } \\
\text { (4) }\end{array}$ & & & & & \\
\hline $\begin{array}{l}\text { While at home } \\
\text { (5) }\end{array}$ & & & & & \\
\hline $\begin{array}{c}\text { When on } \\
\text { vacation (6) }\end{array}$ & & & & & \\
\hline On a date (7) & & & & & \\
\hline $\begin{array}{l}\text { At a gathering } \\
\text { (Party, } \\
\text { Wedding, etc.) } \\
\text { (8) }\end{array}$ & & & & & \\
\hline $\begin{array}{l}\text { While drinking } \\
\text { alcohol (9) }\end{array}$ & & & & & \\
\hline $\begin{array}{l}\text { While using } \\
\text { recreational } \\
\text { drugs (10) }\end{array}$ & & & & & \\
\hline $\begin{array}{l}\text { After arguing } \\
\text { with friend or } \\
\text { family } \\
\text { member(s) } \\
\text { (11) }\end{array}$ & & & & & \\
\hline $\begin{array}{l}\text { After receiving } \\
\text { good news } \\
\text { (12) }\end{array}$ & & & & & \\
\hline $\begin{array}{l}\text { After receiving } \\
\text { bad news (13) }\end{array}$ & & & & & \\
\hline
\end{tabular}


Q18 Have you ever posted something on social media and then regretted doing so?

Yes (1)

No (2)

Q19 How many times has this occurred?

\begin{tabular}{l|l} 
& Number of Occurrences (1) \\
Regretted Posts: (1) & \\
\hline (1) &
\end{tabular}

Q20 Please think about the last time you shared a post or photo on social media and regretted it. Which of the following reasons apply to why you regretted that post/tweet?

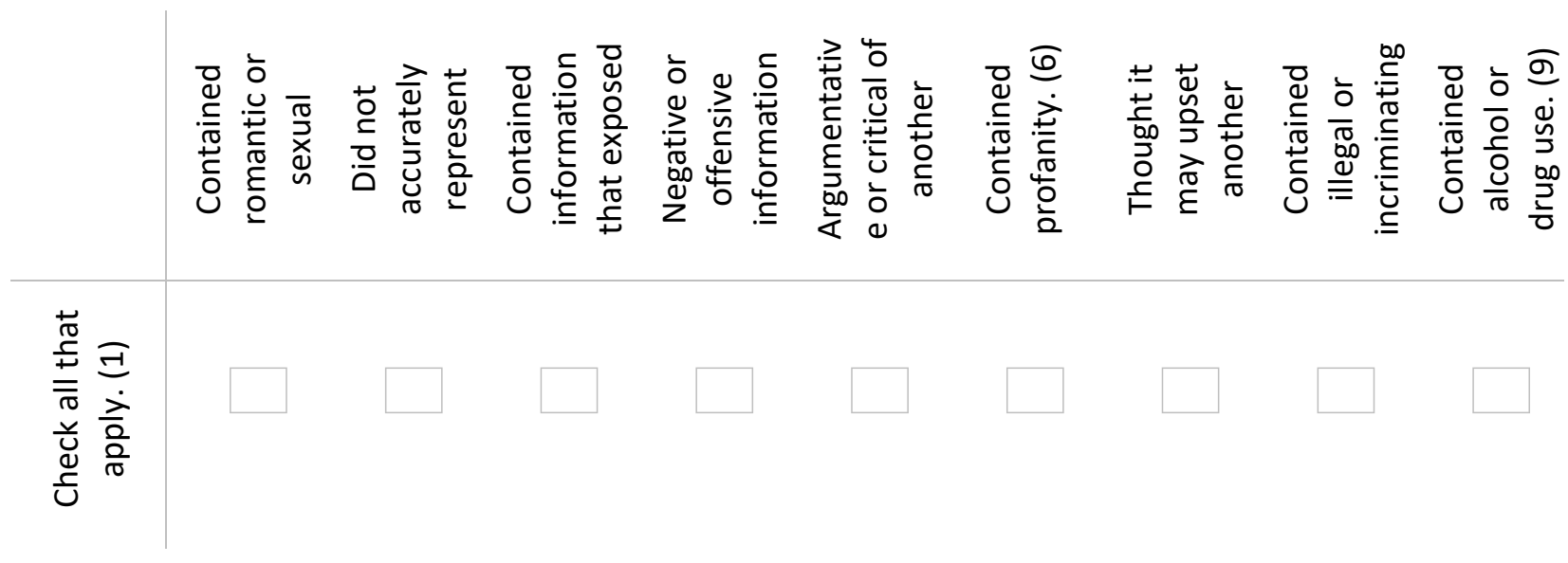


Q21 What types of consequences did you realistically believe may have come from sharing this post/photo/tweet?
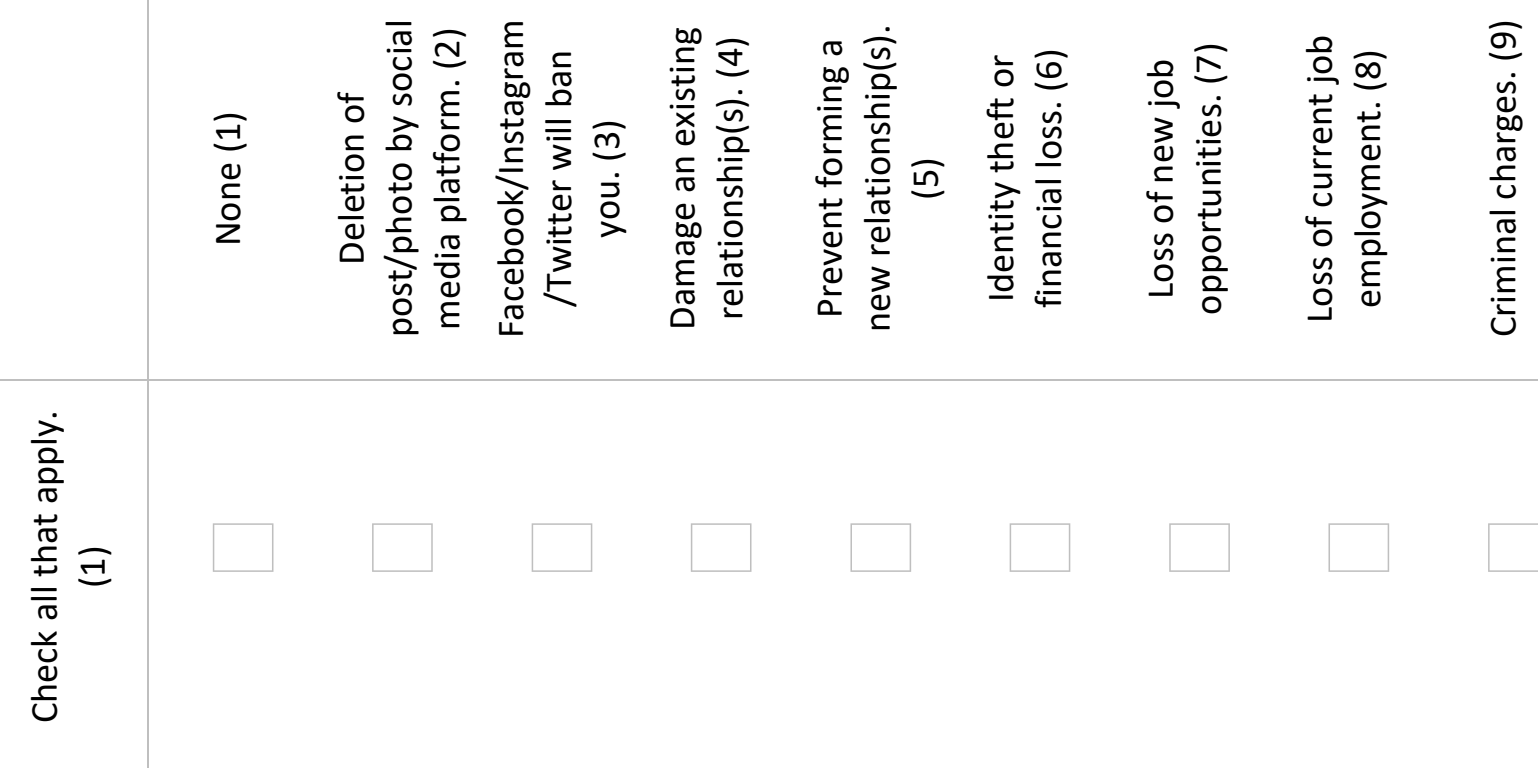

Q22 What specific actions have you taken to address the most recent post that you regret?

Delete posts (1)

Apologize (2)

Stand your ground/defend your post (3)

Unfriend person(s) (4)

Ask others to support your post.

(5)

Change privacy settings (6)

Delete social media account (7) 
Q23 Has another user ever told you that something you posted was offensive, inappropriate, or should be removed?

Yes (1)

No (2)

Q24 How many times has this occurred?

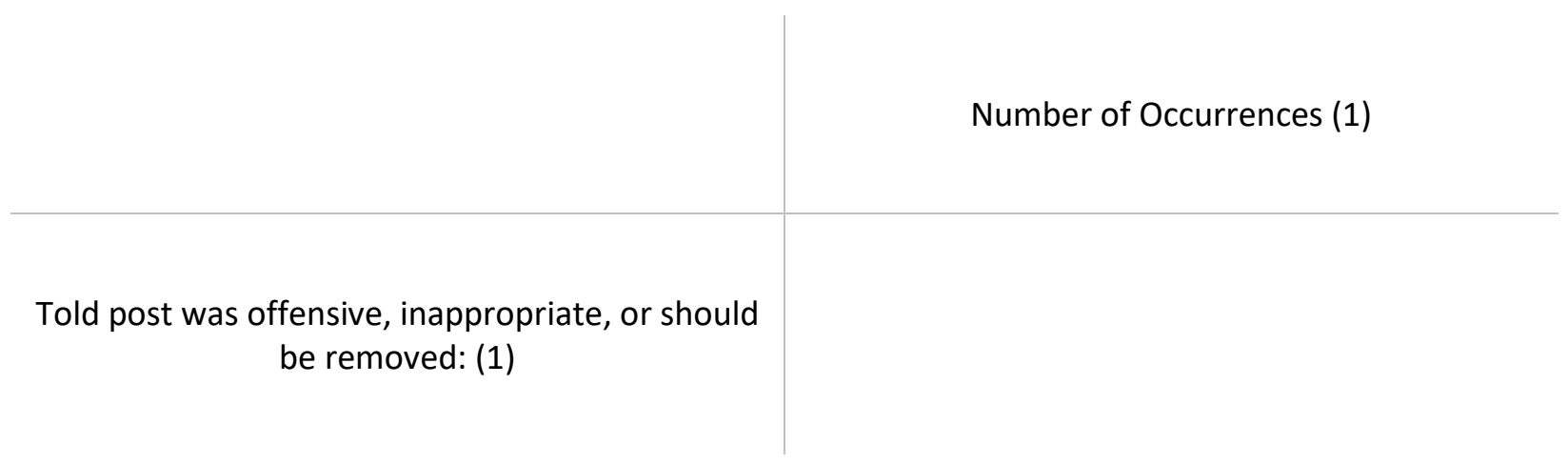

Q25 Please think about the last time you shared something on social media and were told that it was offensive, inappropriate, or should be removed. Which of the following reasons was given to why it was offensive, inappropriate, or should be removed?

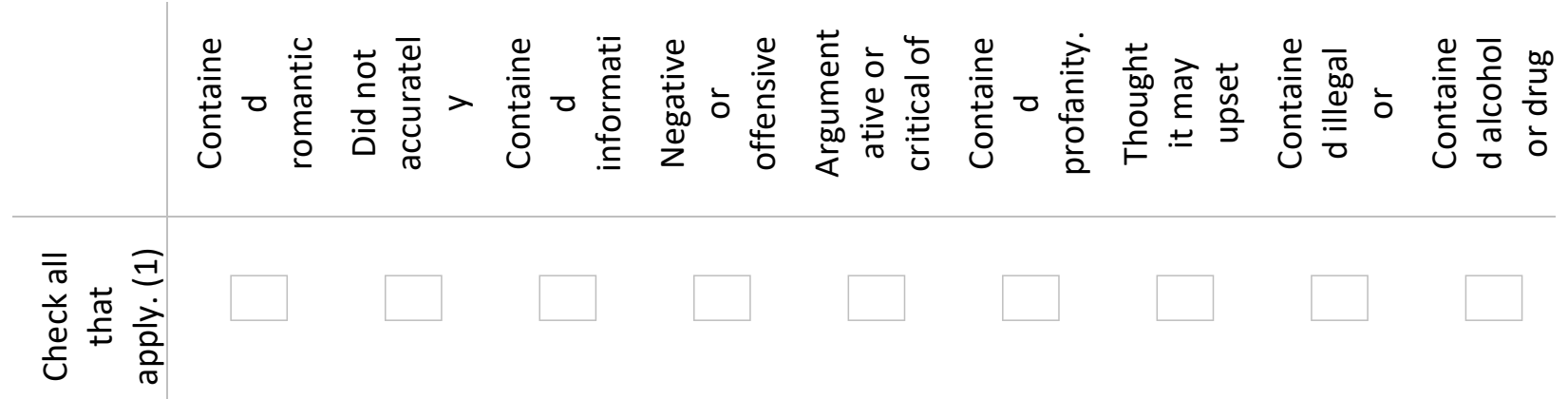


Q26 What types of consequences did you realistically believe may have come from sharing this post/photo/tweet?

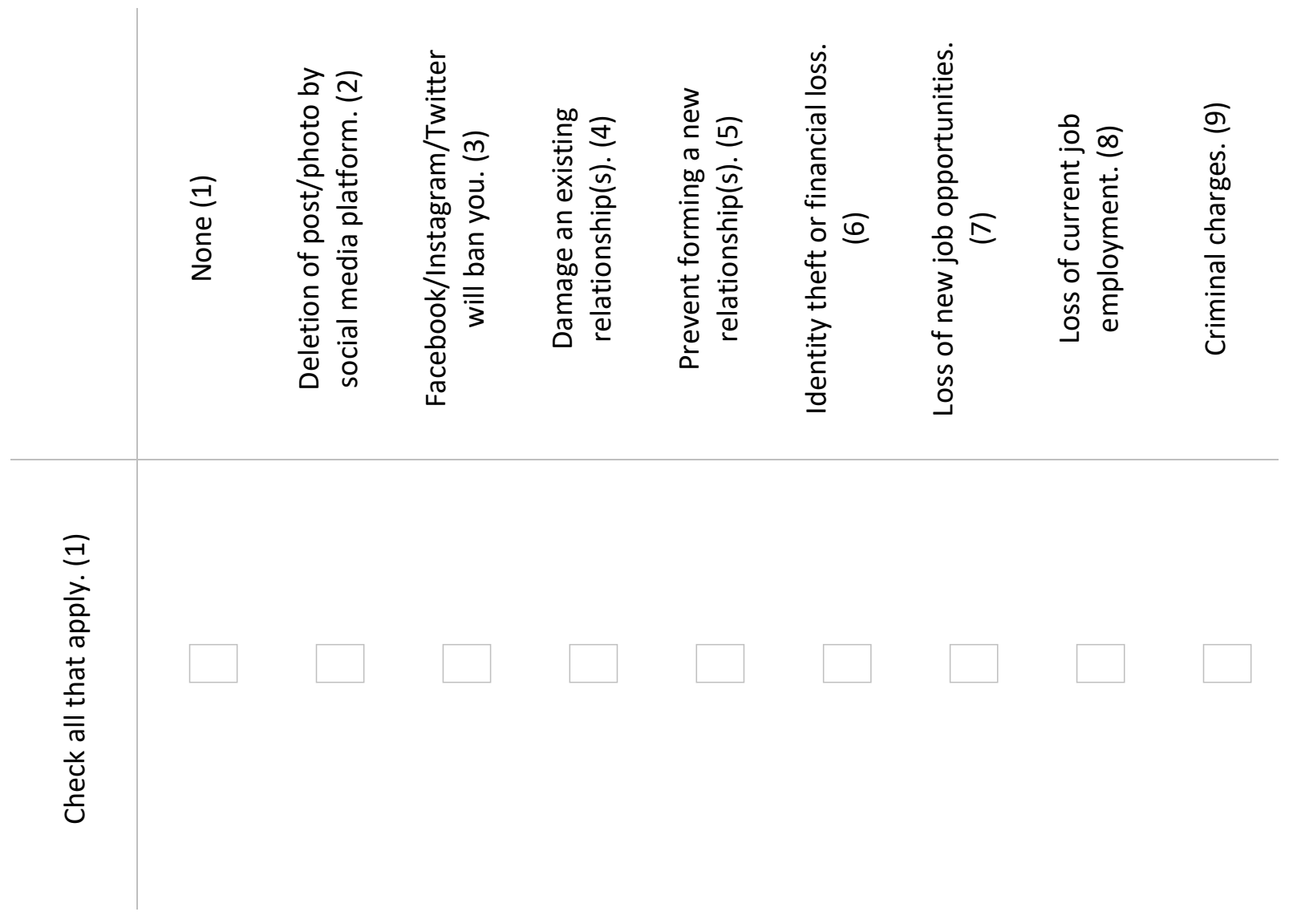


Q27 What specific actions have you taken to address the most recent post that another user told you was offensive, inappropriate, or should be removed?

Took This Action (1)

Considered (2)

Delete posts (1)
Apologize (2)
Stand your ground/defend your
post (3)
Unfriend person(s) (4)
Ask others to support your post.
(5)
Change privacy settings (6)
Delete social media account (7)
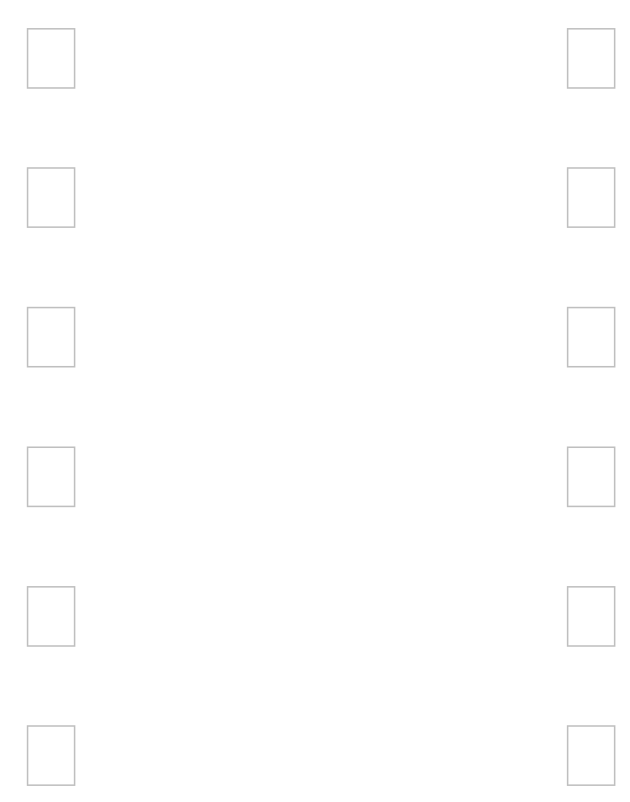

Delete social media account (7) 